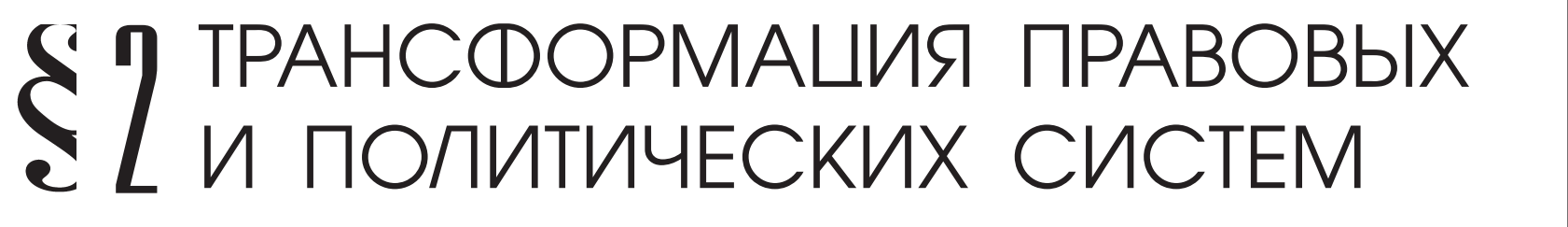

Ранчинская П.О.

\section{СПЕЦИФИКА ВЗАИМОДЕЙСТВИЯ РОССИЙСКОГО И МЕЖДУНАРОДНОГО ПРАВА В ОБЛАСТИ МЕЖДУНАРОДНОГО КОММЕРЧЕСКОГО АРБИТРАЖА}

Аннотация: Автор рассматривает международный коммерческий арбитраж в России а также организованную под его действием связь российской правовой системы с правовыли системами иньх государств. В частности, рассматриваются такие вопросы как : проблема конфиденциальности арбитражного разбирательства, соблюдение принципа соразмерности, проблема исполнения арбитражньх решений, вопросы оформления арбитражного соглашения и нюансы передачи данньх при помощи современных цицрровыхтехнологий. Утверждается что для российского права в данной областихарактерно соблюдение гласных и негласных правил и норм международного права. По мнению автора ситуация с применениеммеждународного права в РФ в немалой степени улучиилась с принятием третьей части ГК РФ, в результате чего российские коллизионные нормы, регулирующие внешнеэкономические сделки, стали отвечать современным тенденциям развития международного частного права. Тем не менее, считает автор пока решение данного вопроса далеко от совериенства. Учитьвая, что российский подход к арбитрабильности споров уже, чем в ряде других стран, существует вероятность отказа иностранньх компаний и их представителей решать споры в России. То есть, автор считает, что попьтки введения жесткого контроля со стороны государственных судебных органов могут привести к ухудшению положения российских компаний, имеюших коммерческие отношения с иностранныл бизнесом. В результате ухода международного арбитража из России вследствие жесткой политики государства будет затронуто имущественное положение предприятий, которье участвуют в спорах. Это приведет кухудиению национальной экономики в целом. С другой стороны, после вступления России в ВТО во взаимоотношения государственных судебных органов и органов системы межсународного коммерческого арбитража в России уже вносятся коррективы. Это позволяет надеяться на успешное преодоление очередного этапа перемен в российском праве..

Review: The author analyzes international commercial arbitration in Russia as well as the connection between the Russian legal system and the legal systems of other states, which was formed due to its influence. In particular, the article concerns such issues as confidentiality of arbitration proceedings, following the proportionality principle, problems of enforcement of arbitration decisions and formation of an arbitration agreement, as well as nuances of data transfer with the use of modern digital technologies. It is stated that it is typical for the Russian law to follow both public and private rules and norms of international law. In the opinion of the author the situation with the application of international law in the Russian Federation was considerably improved after the Part 3 of the Civil Code of the Russian Federation was passed, and the Russian conflict of laws norms on foreign economic deals came into conformance with the modern tendencies of development of the international private law. Nevertheless, the author considers that existing solutions are still far from perfection. Considering that the Russian approach to arbitrability is narrower than it is in a number of other states, there is a possibility that the foreign companies and their representatives shall avoid dispute resolution in Russia. That is, the author considers that the attempts to introduce strict control by state judicial bodies may worsen the position of the Russian companies, having commercial relations with foreign businesses. As a result of the outflow of the international arbitration from Russia due to the strict state policy, the economic situation of enterprises being parties to such disputes shall become worse. It shall lead to worsening of the situation in the national economy as a whole. On the other hand, after Russia has entered the WTO, the relations between the state judicial bodies and international commercial arbitration are being corrected. It allows us to hope to successfully pass another level of changes in the Russian law.

Ключевые слова: Юриспруденция, внешняя торговля, торговый спор, третейский суд, международньий арбитраж, арбитражное соглашение, международный коммерческий спор, национальное законодательство, международный договор, унификация права

Keywords: jurisprudence, foreign trade, trade dispute, arbitration, international arbitration, arbitration agreement, international commercial dispute, domestic legislation, international treaty, unification of law. 
$\mathrm{H}$ аиболее рельефно различие в юридической природе международного коммерческого арбитража и государственного суда проявляется, если согласительного характера арбитража недостаточно для решения процессуальных вопросов ${ }^{1}$. При этом, по мнению экспертов, международный коммерческий арбитраж в России - это единственный институт, связывающий российскую правовую систему с правовыми системами иных государств. За редким исключением Россия не имеет договоров, позволяющих исполнять решения ее государственных судов за рубежом. Аналогичная ситуация складывается и с решениями иностранных судов в России. Можно даже говорить о том, что признание таких решений является проявлением доброй воли, соблюдением своего рода принципа «вежливости»².

Для международного коммерческого арбитража особое значение имеет наличие существенной международно-правовой базы. В основе его работы лежит большое число международных конвенций, которые можно разделить на несколько категорий: конвенции регионального характера, универсальные международные конвенции и документы, многосторонние и двусторонние договоры ${ }^{3}$.

В практике МКАС при ТПП РФ существуют решения, при принятии которых МКАС обращался к Принципам УНИДРУА, но только с целью разрешения конкретного вопроса спора. При этом арбитры применяли Принципы УНИДРУА в качестве критерия, который говорил о существующей международной практике делового оборота, а также использовали их положения учитывая, что Принципы УНИДРУА получают статус торговых обычаев. При этом Принципы УНИДРУА применялись исключительно при решении конкретного вопроса, который возникал в процессе рассмотрения спора и не регулировался применимым правом, или с целью толкования положений международных конвенций. Возможность такого субсидиарного применения Принципов УНИДРУА непосредственно предусмотрена в их преамбуле ${ }^{4}$.

\footnotetext{
${ }^{1}$ Ерпылева Н.Ю. Международный коммерческий арбитраж в международном частном праве: проблемы и перспективы современного развития // Право и политика. 2004. №№ 4, 5.

${ }^{2}$ Кузнеиов О. Итоги-2012. Российские компании в международном арбитраже // РАПСИ. 26.12.12. URL: http://rapsinews.ru/legal_market_publication/20121226/265919336.html

${ }^{3}$ Никифоров, В. А. Международный коммерческий арбитраж в системе третейских судов: История и современное состояние: Автореферат диссертации на соискание ученой степени кандидата юридических наук. - М., 2002.

${ }^{4}$ Бардина М.П. Определение применимых коллизионных норм в практике международного коммерческого арбитраж. В кн.: Кома-
}

Как отмечает А.С. Комаров, основанием для любого арбитражного процесса, международного в том числе, является арбитражное соглашение. Много вопросов и проблем возникает из-за того, что строгие нормы арбитражного соглашения были сформулированы достаточно давно, в те времена, когда не было современных технологий и не было ни Интернета, ни каких иных электронных способов передачи данных. В настоящее время не все российские законы учитывают эти нюансы. Кроме того, необходимо более широкое применение обеспечительных средств, то есть средств обеспечения требований, заявленных в процессе международного арбитража. Это создает предпосылки для использования международного арбитража и укрепляет его позиции в том смысле, что стороне, участвующей в арбитражном разбирательстве, представляется более широкий арсенал средств, направленных на обеспечение тех целей, которые она пытается достичь, используя данный способ разрешения споров 5 .

Ряд международных арбитражных соглашений имеют факультативный характер и они согласованы для применения рядом арбитражных центров с ТПП РФ. В.А. Никифоров подразделяет их на две основные группы:

1. в соответствии с соглашениями первой группы (с корейским, японским, бельгийским и двумя индийскими центрами) споры должны передаваться в постоянно действующий арбитраж страны ответчика; 2. в соответствии с соглашениями второй группы истец может выбирать: обратиться постоянно действующий арбитражный центр страны ответчика, в указанный в соглашении, либо направить спор на рассмотрение арбитража «ad hoc» в соответствии с Арбитражным регламентом Европейской экономической комиссии ООН 1966 г. и Европейской конвенцией о внешнеторговом арбитраже 1961 г. (по соглашению с итальянским центром) или в соответствии с Арбитражным регламентом ЮНСИТРАЛ (по соглашению с австрийским центром). Данные два соглашения позволяют австрийским и итальянским фирмам обращаться с исками как в МКАС при ТПП РФ, так и в МАК при ТПП РФ

ров А.С. (ред.) Международный коммерческий арбитраж: современные проблемы и решения: Сборник статей. М., 2007, с. 28-46.

${ }^{5}$ Интернет-интервью с А.С. Комаровым, Председателем Международного коммерческого арбитражного суда: «Международный коммерческий арбитраж в России: актуальные вопросы практики разрешения споров» // КонсультантПлюс. 16 октября 2007 года. URL: http://www.consultant.ru/law/interview/komarov.html

${ }^{6}$ Никифоров, В. А. Международный коммерческий арбитраж в системе третейских судов: История и современное состояние: 
DOI: $10.7256 / 1811-9018.2013 .10 .9581$

При цитировании этой статьи сноска на доі обязательна

\section{Право и политика $10(166) \cdot 2013$}

Согласно российскому праву, заключение арбитражного соглашения должно проводиться в письменной форме (ст. 7.1. Закона «О международном коммерческом арбитраже» 1993 г., ст. 7. Федерального закона «О третейских судах в Российской Федерации», и, кстати, Нью-Йоркская конвенция 1958 г.)

В России до сих пор не решена проблема исполнения арбитражных решений. Как отмечают эксперты, если решения международного коммерческого арбитража не исполняются добровольно, то должна срабатывать система государственного принуждения, подчеркивая тем самым значимость арбитража, точнее тот факт, что решения данного частного по своему характеру суда, основанного на соглашении сторон, приобретают обязательную силу. Однако для этого государственный суд должен убедиться в том, что арбитражное решениепринято в соответствии спроцедурой, отвечающей обычным требованиям. В частности, например, что исполнение решения не противоречит тому, что в юриспруденции называется публичным порядком. При этом нередко из-за отсутствия опыта судей при оценке решений международного арбитража возникают нестандартные для международного арбитража ситуации, которые должны решаться по-иному. При этом подобные проблемы зачастую возникают из-за того, что российские предприятия, которые должны исполнять решения международного арбитража, используют предусмотренные законом механизмы не для защиты своих прав и восстановления справедливости, а чтобы этими правовыми средствами воспользоваться как механизмом воспрепятствования исполнению решений.

Оговорка о публичном порядке была впервые закреплена в пп. «b» п. 2 ст. V Конвенции Организации Объединенных Наций о признании и приведении в исполнение иностранных арбитражных решений (заключена в г. Нью-Йорке в 1958 г.). Нередко она применяется в российском праве напрямую7. В данной норме Нью-йоркской конвенции отмечено, что в признании и приведении в исполнение арбитражного решения властями страны может быть отказано, если это противоречит публичному порядку самой страны. При этом Президиум ВАС РФ подчеркивает, что данная оговорка о публичном порядке должна применяться только в исключительных

Автореферат диссертации на соискание ученой степени кандидата юридических наук. - М., 2002.

${ }^{7}$ Информационное Письмо Президиума ВАС РФ от 26.02.2013 N 156 «Обзор практики рассмотрения арбитражными судами дел о применении оговорки о публичном порядке как основания отказа в признании и приведении в исполнение иностранных судебных и арбитражных решений» // Высший арбитражный суд PФ. URL: http://www.arbitr.ru/as/pract/vas_info_letter/82122.html случаях, а сам институт публичной оговорки является «экстраординарным средством процессуальной защиты».

В документе также уточняется, что оговорка о публичном порядке может выражаться как в негативном виде (ст. 1193 ГК РФ), так и в позитивном (ст. 1192 ГК РФ). Причем в последнем случае следует говорить о «сверхимперативных нормах российского права». Но и в этом случае, как отмечается в п.п. 1 и 3 Информационного письма $\mathrm{N} 156$, противоречие иностранного судебного или арбитражного решения российским сверхимперативным нормам будет являться нарушением публичного порядка. Бремя доказывания нарушения публичного порядка при этом лежит на той стороне, которая заявляет о таком нарушении (п. 3 Информационного письма N 156).

Иностранное судебное или арбитражное решение противоречит публичному порядку, если оно:

- наносит ущерб безопасности или суверенитету государства;

- противоречит сверхимперативным нормам российского права;

- нарушает конституционные свободы и права частных лиц;

- $\quad$ затрагивает интересы крупных социальных групп ${ }^{8}$. При этом российский суд не может ссылаться на нарушение российского публичного порядка, если в решении заложен принцип соразмерности, то есть зафиксировано применение норм иностранного права, которые могут быть использованы не только в компенсационных целях. В соответствии с п. 6 Информационного письма N 156 данная ситуация может складываться при наличии следующих условий:

- если при согласовании размера убытков имелись явные признаки злоупотребления свободой договора (например, при слабых переговорных возможностях должника, а также при нарушении публичных интересов и интересов третьих лиц и т.п.);

- если убытки настолько велики, что многократно превышают размер, который стороны разумно предвидели при заключении договора9 .

Принципу соразмерности также не соответствует односторонняя реституция, так как носит конфискационную природу, а это противоречит российскому публичному порядку (Постановление ФАС Центрального округа от 21.01.2009 по делу N A09-7012/2008-35).

Еще один вопрос, возникающий на стыке российского обычного и международного коммерческого права - это во-

\footnotetext{
8 Там же

9 Там же.
} 
прос конфиденциальности арбитражного разбирательства. Конфиденциальность - обычное правило для международного коммерческого арбитража. Это позволяет предпринимателям сохранять коммерческую тайну. Но если речь идет об инвестиционном споре, гдезадействовано государство и, особенно в случае, если государство проиграет спор, то оно должно будет оплачивать суммы, признанные в пользу иностранных инвесторов, из государственных денег, то есть из средств налогоплательщиков. И в этом случае говорить о конфиденциальности нет оснований.

Как было сказано выше, при обращении к международному коммерческому арбитражу, прежде всего, принимается арбитражное соглашение, то есть происходит определение нормы права, выбор применимого права, определяющего критерии оценки позиций сторон и оказывающего влияние на принятие решения. Ключевым принципом в данной области является выбор права сторонами контракта. При этом понятие «нормы права» не ограничены национальным правом и включает в себя также нормы вненационального регулирования, в частности, Принципы международных коммерческих договоров УНИДРУА $^{10}$. При отсутствии указания сторон о выборе права данный вопрос решается арбитрами международного коммерческого арбитража. Арбитры же решают на основе каких коллизионных норм будет произведен выбор права.

М.П. Бардина выделяет следующие источники коллизионных норм для норм права, которые использует МКАС при ТПП РФ:

- «формула Конвенции 1961 г.», входящая в российскую правовую систему в виде нормы международного договора, в котором участвует РФ;

- З Закон РФ «О международном коммерческом арбитраже» 1993 г., учитывающий положения Типового закона ЮНСИТРАЛ 1985 г. и воспроизводящий в п. 2 ст. 28 своего текста положение п. 2 ст. 28 Типового закона ЮНСИТРАЛ 1985 г.;

- вводная статья 1186 разд. VІГК РФ «Международное частное право». П. 1 ст. 1186 определяет особенности применения права международным коммерческим арбитражем ${ }^{11}$.

\footnotetext{
${ }^{10}$ Прогрессивное развитие унификации правовых норм о международных коммерческих сделках (вступительная статья) / Принципы международных коммерческих договоров УНИДРУА 2004 / Пер. с англ. А.С. Комарова. М.: Статут, 2006; Бардина М.П. Особенности определения права, подлежащего применению международным коммерческим арбитражем // Международное публичное и частное право. 2003. № 5. С. 18-19.

${ }^{11}$ Бардина М.П. Определение применимых коллизионных норм в практике международного коммерческого арбитраж. В кн.:
}

Несмотря на наличие правовой базы и признания свободы выбора коллизионных норм, МКАС в большинстве случаев признает применимыми российские коллизионные нормы, которые действовали в РФ на момент заключения контракта, вызвавшего спор.

После принятия третьей части ГК РФ российские коллизионные нормы, определяющие право, которое применимо к внешнеэкономическим сделкам, стали отвечать современным тенденциям развития международного частного права, и представляют собой детально проработанное коллизионное регулирование. Так, гибкий подход в определении применимого права обеспечивает статья 1211 ГК РФ, так как презюмирует, право какой страны является более тесно связанным с договором. При этом ГК исходит из права страны, где находится основное место деятельности исполняющей решение стороны. Статья 1211 разрешает отступление от предложенного критерия, если иное вытекает из закона, существа или условий договора или совокупности обстоятельств дела. На тех же условиях возможно отступление от предложенной в п. 3 ст. 1211 презумпции того, кто считается стороной, осуществляющей исполнение, которая имеет решающее значение для содержания 19 договоров ${ }^{12}$.

В Арбитражно-процессуальном кодексе также существует положение, которое касается порядка осуществления государственного контроля за международным коммерческим арбитражем, то есть нормы, регулирующие судебный порядок оспаривания решений, принятых международным коммерческим арбитражем и нормы, которые касаются процедуры приведения в исполнение международных арбитражных решений. Так, на недопустимость пересмотра иностранного судебного и арбитражного решения указывается в ч. 4 ст. 243 АПК РФ. Перечень оснований для отказа в экзекватуре иностранного арбитражного или судебного решения приведен в ст. 244 АПК РФ.

Президиум ВАС РФ также обращает внимание на то, что российский государственный суд имеет право оценивать только последствия исполнения иностранного судебного или арбитражного решения в процессе анализа резолютивной части иностранного судебного или арбитражного решения. А попытка подвергнуть мотивировочную часть решения анализу - на соответствие рос-

Комаров А.С. (ред.) Международный коммерческий арбитраж: современные проблемы и решения: Сборник статей. М., 2007, c. $28-46$.

${ }^{12}$ Бардина М.П. Определение применимых коллизионных норм в практике международного коммерческого арбитраж. В кн.: Комаров А.С. (ред.) Международный коммерческий арбитраж: современные проблемы и решения: Сборник статей. М., 2007, c. $28-46$. 
DOI: $10.7256 / 1811-9018.2013 .10 .9581$

При цитировании этой статьи сноска на dоі обязательна

\section{Право и политика $10(166) \cdot 2013$}

сийскому публичному порядку, например - является по сути своей скрытым пересмотром данного дела ${ }^{13}$. То есть, заниматься повторной оценкой фактов и доказательств, представленных и рассмотренных в иностранном суде или арбитраже, государственный суд не может.

В целом, говоря о взаимодействии российского и международного права в области коммерческого арбитража можно использовать классификацию подходов, разработанную Н.Ю. Ерпылевой, согласно которой выделяется три основных точки зрения на данную проблему:

1. договорная концепция юридической природы арбитража, в соответствии с которой арбитражное соглашение, лежащее в основе передачи спора на разрешение в арбитраж, представляет собой обычный гражданско-правовой договор. Договорный характер такого соглашения определяет договорную природу самого арбитража. Это позволяет утверждать о возможности постановки коллизионной проблемы (например, по вопросам о форме арбитражного соглашения, основаниях его недействительности, правосубъектности сторон такого соглашения), что создает предпосылки для применения иностранного права;

2. процессуальная концепция, в соответствии с которой арбитраж признается в качестве особой формы правосудия, осуществляемой от имени государства. Элемент государственности заключается в том, что ряд вопросов арбитражного процесса может быть разрешен только при участии государственных судебных органов. В частности, вопросы о признании и исполнения арбитражного решения. В этом случае должно применяться право того государства, на территории которого происходит арбитражное разбирательство или к суду которого сделаны соответствующие обращения. В реальности применение только внутригосударственного (национального) права исключает постановку коллизионной проблемы;

3. смешанная концепция сочетает в себе основные положения двух предыдущих концепций. Таким образом, она рассматривает арбитраж как самостоятельный институт, который включает в себя как материально-правовые, так и процессуально-

${ }^{13}$ Информационное Письмо Президиума ВАС РФ от 26.02.2013 N 156 «Обзор практики рассмотрения арбитражными судами дел о применении оговорки о публичном порядке как основания отказа в признании и приведении в исполнение иностранных судебных и арбитражных решений» // Высший арбитражный суд PФ. URL: http://www.arbitr.ru/as/pract/vas_info_letter/82122.html правовые элементы. И если к единому арбитражному соглашению будет применяться комплекс коллизионных норм, то следует говорить о «ситуации расщепления коллизионных привязок», так как вопросы взаимоотношений арбитража и государственного суда будут разрешаться на основании процессуального права того государства, на территории которого имеет место арбитражное разбирательство, или того государства, где испрашивается исполнение арбитражного решения ${ }^{14}$.

Эксперты при этом отмечают, что в России подход к арбитрабильности споров в целом уже, чем в ряде стран с развитой рыночной экономикой. Общее количество видов международных споров, которые не могут являться предметом арбитражного разбирательства, в России больше, чем в большинстве других стран. В частности, в развитых странах практически любой коммерческий спор между организациями, тем более, если он является международным спором, является арбитрабильным. А в России государственные арбитражные суды еще ограничивают арбитрабильность. И подобное отношение к решениям международных судов в России может стать причиной того, что иностранцы откажутся решать коммерческие споры в России. Результатом может стать необходимость решения споров с участием российских предпринимателей за рубежом с соответствующей оплатой за это и с неуверенностью в исходе дела. Данного результата следует ожидать при попытках введения жесткого контроля со стороны государственных судов над международным арбитражем ${ }^{15}$.

Правда, следует отметить, что жесткий судебный контроль уже не столь характерен для современных условий, а российское законодательство при этом должно отвечать международным стандартам, так как оно принято на основе Типового закона Комиссии ООН по праву международной торговли (ЮНСИТРАЛ). Кроме того, уход международного арбитража из России вследствие жесткой политики отразится, прежде всего, на имущественном положении предприятий, которые участвуют в спорах, и на национальной экономике в целом.

\footnotetext{
${ }^{14}$ Ерпылева Н.Ю. Международный коммерческий арбитраж в международном частном праве: проблемы и перспективы современного развития // Право и политика. 2004. №№ 4, 5.

${ }^{15}$ Интернет-интервью с А.С. Комаровым, Председателем Международного коммерческого арбитражного суда: «Международный коммерческий арбитраж в России: актуальные вопросы практики разрешения споров» // КонсультантПлюс. 16 октября 2007 года. URL: http://www.consultant.ru/law/interview/komarov.html
} 
Таким образом, можно констатировать тот факт, что в российском праве на грани взаимодействия его с международным правом в области международного арбитража сочетаются гласные и негласные правила и нормы. И хотя и та, и другая категории норм регулируются российскими или международными документами, они оставляют достаточно широкое поле для их применения. Перемены, происходящие в последнее время в стране и, в частности, вступление в ВТО уже вносят свои коррективы во взаимоотношения государственных судебных органов и органов системы международного коммерческого арбитража в России. Только изначальная гибкость данной системы позволяет надеяться на успешное преодоление очередного этапа перемен в российском праве.

\section{Библиография:}

1. Бардина М.П. Определение применимых коллизионных норм в практике международного коммерческого арбитраж. В кн.: Комаров А.С. (ред.) Международный коммерческий арбитраж: современные проблемы и решения: Сборник статей. М., 2007, c. 28-46.

2. Бардина М.П. Особенности определения права, подлежащего применению международным коммерческим арбитражем // Международное публичное и частное право. 2003. № 5. С. 18-19.

3. Ерпылева Н.Ю. Международный коммерческий арбитраж в международном частном праве: проблемы и перспективы современного развития // Право и политика. 2004. №№ 4, 5.

4. Кабатов В.А. Выбор применимого права // эжЮрист. 2001. № 42.

5. Кузнецов О. Итоги-2012. Российские компании в международном арбитраже // РАПСИ. 26.12.12. URL: http://rapsinews.ru/legal_market_publication/20121226/265919336.html

6. Никифоров, В. А. Международный коммерческий арбитраж в системе третейских судов: История и современное состояние: Автореферат диссертации на соискание ученой степени кандидата юридических наук.-М., 2002.

7. Николюкин С.В. Международный коммерческий арбитраж. М.: Юстицинформ, 2009.

8. Розенберг М.Г. Международный договор и иностранное право в практике Международного коммерческого арбитражного суда. М.: Статут, 2000.
9. Ситкарева Е.В. Противоречие публичному порядку как основание отмены решения международного коммерческого арбитража // Право и политика. 2004. №10.

10. Скворцов О.Ю. Третейское разбирательство предпринимательских споров в России: проблемы, тенденции, перспективы.-Волтерс Клувер, 2005.

\section{References (transliteration):}

1. Bardina M.P. Opredelenie primenimykh kollizionnykh norm $\mathrm{v}$ praktike mezhdunarodnogo kommercheskogo arbitrazh. V kn.: Komarov A.S. (red.) Mezhdunarodnyi kommercheskii arbitrazh: sovremennye problemy i resheniya: Sbornik statei. M., 2007, s. 28-46.

2. Bardina M.P. Osobennosti opredeleniya prava, podlezhashchego primeneniyu mezhdunarodnym kommercheskim arbitrazhem // Mezhdunarodnoe publichnoe i chastnoe pravo. 2003. № 5. S. 18-19.

3. Erpyleva N.Yu. Mezhdunarodnyi kommercheskii arbitrazh v mezhdunarodnom chastnom prave: problemy $\mathrm{i}$ perspektivy sovremennogo razvitiya // Pravo i politika. 2004. №№ 4, 5.

4. Kabatov V.A. Vybor primenimogo prava // ezh-Yurist. 2001. № 42.

5. Kuznetsov O. Itogi-2012. Rossiiskie kompanii v mezhdunarodnom arbitrazhe // RAPSI. 26.12.12. URL: http://rapsinews.ru/legal_market_publication/20121226/265919336.html

6. Nikiforov, V. A. Mezhdunarodnyi kommercheskii arbitrazh $\mathrm{v}$ sisteme treteiskikh sudov: Istoriya $\mathrm{i}$ sovremennoe sostoyanie: Avtoreferat dissertatsii na soiskanie uchenoi stepeni kandidata yuridicheskikh nauk. - M., 2002.

7. Nikolyukin S.V. Mezhdunarodnyi kommercheskii arbitrazh. M.: Yustitsinform, 2009.

8. Rozenberg M.G. Mezhdunarodnyi dogovor i inostrannoe pravo v praktike Mezhdunarodnogo kommercheskogo arbitrazhnogo suda. M.: Statut, 2000.

9. Sitkareva E.V. Protivorechie publichnomu poryadku kak osnovanie otmeny resheniya mezhdunarodnogo kommercheskogo arbitrazha // Pravo i politika. 2004. №10.

10. Skvortsov O.Yu. Treteiskoe razbiratel'stvo predprinimatel'skikh sporov v Rossii: problemy, tendentsii, perspektivy. - Volters Kluver, 2005. 